\title{
Alfentanil does not increase resistance of the respi- ratory system in ASA I patients ventilated mechanically during general anesthesia
}

\author{
[L'alfentanil n'augmente pas la résistance du système respiratoire chez des patients \\ d'état physique ASA I ventilés mécaniquement pendant l'anesthésie générale]
}

Giorgio Conti MD, Germano De Cosmo MD, Maria Grazia Bocci MD, Massimo Antonelli MD, Giorgia Ferro MD, Roberta Costa MD, Geremia Zito MD, Rodolfo Proietti MD

Purpose: Several experimental and clinical studies have demonstrated a direct bronchoconstrictor effect of opioids on smooth bronchial musculature following iv administration.

The aim of this study was to evaluate the effects of alfentanil on respiratory system mechanics in a group of ASA I patients ventilated mechanically during general anesthesia.

Clinical features: Twenty consecutive ASA I patients (ten men and ten women) scheduled for general surgery interventions were studied (mean age $45.4 \pm 9.9 \mathrm{yr}$, mean weight $61.9 \pm 6.7 \mathrm{~kg}$ ). Exclusion criteria were a history of chronic obstructive pulmonary disease, asthma or other pulmonary disease, atopy, wheezes, smoking and age below 18 yr. Subjects were randomly divided in two groups: Group A, receiving alfentanil at a $15 \mu \mathrm{g} \cdot \mathrm{kg}^{-1}$ dose and Group B receiving alfentanil at a $30 \mu \mathrm{g} \cdot \mathrm{kg}^{-1}$ dose. Respiratory mechanic variables were acquired at baseline (TO) and after three, ten and $15 \mathrm{~min}$ (TI, T2 and T3, respectively). We compared the basal values to the values measured at each time interval; basal values, prior to drug administration, served as control for each patient. $P$ values $<0.05$ were considered statistically significant.

Results: We did not observe significant differences in respiratory mechanic variables after the administration of alfentanil, 15 and 30 $\mu \mathrm{g} \cdot \mathrm{kg}^{-1}$. More specifically, respiratory system compliance and the different subcomponents of respiratory system resistances (i.e., maximum, minimum and delta resistance of respiratory system) were within normal limits and did not vary after alfentanil administration.

Conclusion: No respiratory adverse effect was reported after alfentanil iv administration.
Objectif : De nombreuses études expérimentales et cliniques ont démontré un effet bronchoconstricteur direct des opiö̈des intraveineux sur la musculature lisse bronchique. Le but de notre étude était d'évaluer les effets de l'alfentanil sur la mécanique du système respiratoire chez un groupe de patients ASA I ventilés mécaniquement pendant une anesthésie générale.

Éléments cliniques : Vingt patients consécutifs ASA I ont été étudiés (dix hommes) pendant une intervention de chirurgie générale (âge moyen 45,4 \pm 9,9 ans, poids moyen 61,9 \pm 6,7 kg). Les critères d'exclusion étaient : un historique de bronchite chronique obstructive, asthme ou autres maladies pulmonaires, allergies, tabagisme, sibilances à l'auscultation pulmonaire et un âge inférieur à 18 ans. Les sujets ont été randomisés en deux groupes : Groupe A, recevant $15 \mu \mathrm{g} \cdot \mathrm{kg}^{-1}$ d'alfentanil et Groupe B recevant $30 \mu \mathrm{g} \cdot \mathrm{kg}^{-1}$ d'alfentanil. Les variables de la mécanique respiratoire ont été mesurés au départ (TO) et après trois, dix et $15 \mathrm{~min}$ ( $T 1$, T2 et T3, respectivement). Les données de base ont été comparées avec les données mesurées après chaque intervalle de temps, les valeurs de $P<0,05$ ont été jugées statistiquement significatives.

Résultats : Aucune différence significative entre les variables de mécanique respiratoire n'a été observée après l'administration d'alfentanil, aussi bien après une dose de 15 que de $30 \mu \mathrm{g} \cdot \mathrm{kg}^{-1}$. En particulier, la compliance du système respiratoire et les différentes variables des composantes des résistances du système respiratoire (les résistances maximale, minimale et delta du système respiratoire) se situaient dans des limites normales et n'ont pas montré de variations significatives après alfentanil.

Conclusion : Aucun effet secondaire sur la mécanique respiratoire n'a été remarqué après l'administration iv d'alfentanil.

From the Department of Anesthesia, University of Cattolica del Sacro Cuore di Roma, Policlinico Universitario "A. Gemelli”, Rome, Italy. Address correspondence to: Dr. Giorgio Conti, Istituto di Anestesia e Rianimazione dell', Università Cattolica del "Sacro Cuore" di

Roma, Largo F. Vito 1, 00168 Rome, Italy. Phone: +39 06 30154386; Fax: +39 06 3013450; E-mail: g.conti @rm.unicatt.it Accepted for publication January 28, 2002.

Revision accepted May 13, 2002. 


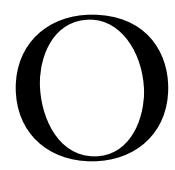

PIOIDS are widely used in clinical anesthesia, both to reduce the requirements of inhalation agents, and to provide intra- and postoperative analgesia. However, opioid administration may have significant repercussions on respiratory function.

Beside respiratory depression, several experimental and clinical studies demonstrated a direct bronchocostrictor effect of opioids on smooth bronchial musculature following iv administration. ${ }^{1,2}$ The consequent increase in bronchial tone could be particularly harmful during general anesthesia, when it can cause an increase in airway pressure, and increase the risk of ventilation-induced barotrauma. ${ }^{3,4}$

Alfentanil is a central analgesic, belonging to the 4amydo pirydines; it is active predominantly on mureceptors and its analgesic effect is 70 -fold higher than that of morphine, and does not cause histamine release. ${ }^{5}$ The maximal analgesic effect appears within one minute after bolus iv administration. The rapid onset and the rapid offset of its pharmacological action make alfentanil suitable during balanced anesthesia, to control the neuroendocrine response to surgical stress. The administration of alfentanil $\left(5-50 \mu \mathrm{g} \cdot \mathrm{kg}^{-1}\right)$ significantly reduces hemodynamic responses to laryngoscopy, endotracheal intubation and surgical incision. ${ }^{6}$

In spite of the great number of studies dedicated to the use of opioids during anesthesia, few data are available regarding the effects of last generation opioids on respiratory mechanics under general anesthesia. ${ }^{7-9} \mathrm{~A}$ previous study has evaluated the effects on respiratory mechanics of high-dose alfentanil administration in patients undergoing cardiac surgery. ${ }^{10}$

The aim of this study was to evaluate the effects of alfentanil administration on respiratory system mechanics in a group of ASA I patients mechanically ventilated during general anesthesia for general surgery.

\section{Methods}

Patients

After approval of our Institutional Ethics Committee and informed consent, 20 consecutive ASA I patients (ten men and ten women) scheduled for general surgery (mean age $45.4 \pm 9.9 \mathrm{yr}$, mean weight $61.9 \pm$ $6.7 \mathrm{~kg}$ ) were enrolled. This sample size was chosen in accordance to the Neto et al. study. ${ }^{10}$

Exclusion criteria were a history of chronic obstructive pulmonary disease, asthma or other pulmonary disease, atopy, wheezes, smoking of tobacco and age below $18 \mathrm{yr}$. All patients presenting an expected risk of difficult intubation were excluded from the study.

Subjects were randomly divided (computer generated randomization) in two groups: Group A, receiv- ing alfentanil $15 \mu \mathrm{g} \cdot \mathrm{kg}^{-1}$, and Group B receiving alfentanil $30 \mu \mathrm{g} \cdot \mathrm{kg}^{-1}$.

Alfentanil was administered as an $i v$ bolus, after the induction of general anesthesia. All measurements were performed before surgical manipulations.

\section{Experimental protocol}

After preoxygenation for five minutes via face mask $\left(\mathrm{FIO}_{2}=1\right)$, anesthesia was induced with sodium thiopental $\left(8 \mathrm{mg} \cdot \mathrm{kg}^{-1}\right)$ and maintained for a few minutes with a continuous infusion of sodium thiopental at the dose of $8 \mathrm{mg} \cdot \mathrm{kg}^{-1} \cdot \mathrm{min}^{-1}$. Cis-atracurium $0.2 \mathrm{mg} \cdot \mathrm{kg}^{-1}$, was administered to facilitate endotracheal intubation, after the disappearance of the $\mathrm{Tl}$ response of the train-of-four (TOF) stimulation, as measured by acceleromyography with the TOF Guard (Organon Teknika, The Netherlands). Cis-atracurium was chosen for its lack of histamine release properties at clinical doses. ${ }^{11}$

Standard monitoring included noninvasive arterial pressure, heart rate, $\mathrm{SpO}_{2}$, end-tidal $\mathrm{CO}_{2}$. Patients were ventilated in intemittent pressure positive ventilation mode with a Siemens Servo Ventilator 900C/ SiemensElema, Sweden ${ }^{12}$ with the following setting: tidal volume $10 \mathrm{~mL} \cdot \mathrm{kg}^{-1}, \mathrm{FIO}_{2}=0.5$, respiratory rate 10 breaths. $\mathrm{min}^{-1}$, zero end expiratory pressure, I:E ratio $\mathrm{l}-2$. The ventilatory circuit included standard tubing, and the endotracheal tube (internal diameter from $7-8 \mathrm{~mm}$ ).

\section{Respiratory mechanics measurements}

Under general anesthesia with paralysis and constant flow controlled mechanical ventilation, a three second end- inspiratory airway occlusion, performed by pressing the dedicated ventilator button, ${ }^{13,14}$ causes a biphasic decay of the pressure in the respiratory system, from a maximum value (Pmax) to a value of pressure called Pl. Minimal resistance of the respiratory system (RRSmin), mainly representing airway resistance, can be calculated as the difference between Pmax and Pl divided by the inspiratory flow (Figure 1). ${ }^{15,16}$

A further, slower decay of the pressure in the airways, from Pl to a plateau value P2 is then observed, reflecting the forces resulting from the elastic recoil of the respiratory system, at the end of the inspiratory phase. The total RRSmax can be calculated by dividing Pmax - P2 by the inspiratory flow. Finally, by subtracting RRSmin from RRSmax it is possible to calculate deltaRRS, mainly representing the visco-elastic resistance of the respiratory system. ${ }^{17,18}$

Airway pressure signal is measured at the level of the carina with an air-filled non-compliant catheter (1.2 $\mathrm{mm}$ internal diameter), provided with multiple side holes and an occluded terminal lumen, placed inside the endotracheal tube. ${ }^{19}$ 

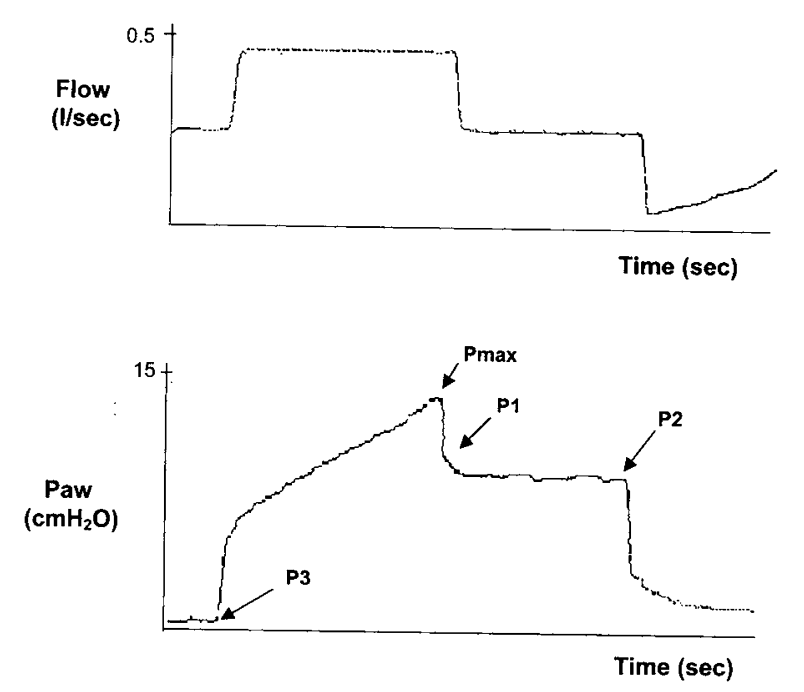

FIGURE 1 Schematic representation of an airflow and airway pressure tracing for assessment of resistances (see text for details).

The analysis of respiratory system mechanics is then completed by calculating respiratory system compliance (Crs), that is obtained by dividing the tidal volume (TV) by the difference between P2 and the tele-expiratory pressure (P3), after checking for the absence of auto-positive end-expiratory pressure (Figure 1).

Respiratory mechanics variables were acquired using a Bicore pulmonary system CP-100 (Irvine, CA, USA) connected to the endotracheal tube at the $\mathrm{Y}$ piece. ${ }^{20}$ Data were recorded using a channel for airway pressure, a channel for air flow, and a third channel for TV; volume was obtained by electronic integration of flow signal over time; airway pressure was evaluated at the carinal level, ${ }^{19}$ to eliminate a bias secondary to the possible modification of tube resistance (by kinking, secretions or displacement); this was not done in the previous study published by Neto et al., ${ }^{10}$ where airway pressure was measured inside the ventilator expiratory line.

The pulmonary monitor was connected to an Intel based personal computer using a RS232 standard serial connection. Acquisition was performed with a software Bicore CP-100 version 2.0 (Bicore Monitoring Systems 2 Faraday Irvine, CA, USA)..$^{20}$ Collected data were then converted into ASCII format for further analysis. Analysis of collected data was performed using Anadat ${ }^{\mathrm{TM}}$ version 5.1 by RHT-InfoDat Inc. (Montréal, Québec, Canada).

After obtaining basal measurements (T0), alfentanil was administered. Respiratory mechanics variables

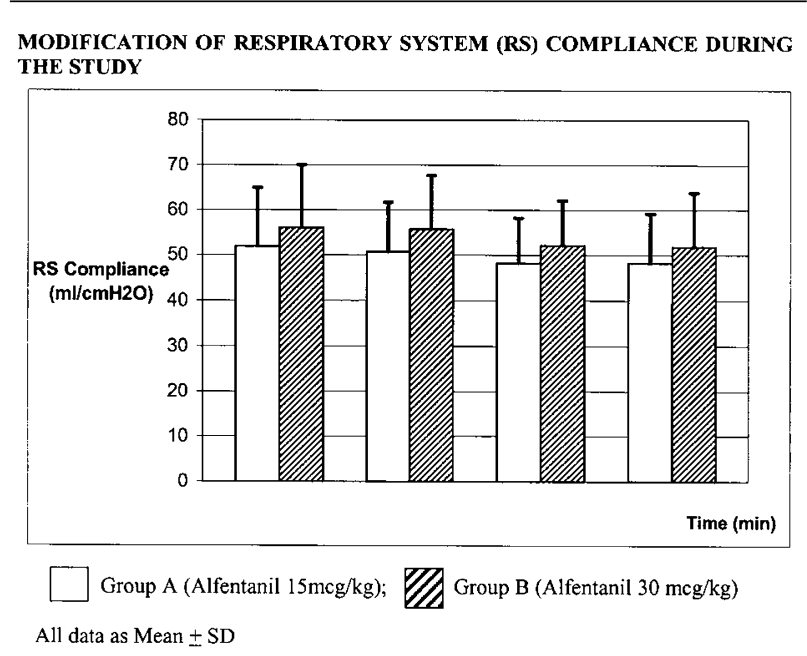

FIGURE 2 Modification of respiratory system (RS) compliance during the study. Empty columns = Group A (alfentanil 15 $\left.\mu \mathrm{g} \cdot \mathrm{kg}^{-1}\right)$; Hatched columns $=$ Group B (alfentanil $\left.30 \mu \mathrm{g} \cdot \mathrm{kg}^{-1}\right)$. All data as mean $\pm \mathrm{SD}$.

were acquired after three, ten and $15 \mathrm{~min}(\mathrm{~T} 1, \mathrm{~T} 2$ and T3 respectively). This short time of observation was chosen to minimize the risk of a type II error due to the progressive decrease in functional residual capacity observed over time in supine patients ventilated mechanically during general anesthesia. ${ }^{15}$ All measurements were performed in triplicate.

\section{Statistical analysis}

Mean values and standard deviation of Crs, RRSmin, RRSmax and deltaRRS, in the two groups of patients, were calculated for each time interval (T0, T1, T2, T3).

Statistical analysis was performed using one-way repeated measure Anova. Post hoc comparison was performed using paired $t$ test. We compared the basal values to the values measured at each time interval; $P$ values $<0.05$ were considered statistically significant.

\section{Results}

The results of the study are presented in Tables I, II and in Figure 2, expressed as mean \pm SD. We did not observe any statistically significant differences in respiratory mechanics variables after the administration of alfentanil 15 and $30 \mu \mathrm{g} \cdot \mathrm{kg}^{-1}$.

More specifically, the values of Crs (Figure 2) and of the different components of respiratory system resistances (i.e., RRSmax, RRSmin and deltaRRS) were within standard limits for intubated patients and did not show variations after alfentanil administration. ${ }^{18}$ 
TABLE I RRS in patients receiving alfentanil

\begin{tabular}{|c|c|c|c|c|c|c|}
\hline & \multicolumn{2}{|c|}{$\begin{array}{c}\text { RRSmin } \\
\left(\mathrm{cm} \mathrm{H}_{2} \mathrm{O} \cdot L^{-1} \cdot \sec ^{-1}\right)\end{array}$} & \multicolumn{2}{|c|}{$\begin{array}{c}\text { RRSmax } \\
\left(\mathrm{cm} \mathrm{H}_{2} \mathrm{O} \cdot L^{-1} \cdot \sec ^{-1}\right)\end{array}$} & \multicolumn{2}{|c|}{$\begin{array}{c}\text { DeltaRRS } \\
\left(\mathrm{cm} \mathrm{H} \mathrm{H}_{2} \mathrm{O} \cdot \mathrm{L}^{-1} \cdot \mathrm{sec}^{-1}\right)\end{array}$} \\
\hline & Group $A$ & Group B & Group $A$ & Group B & Group $A$ & Group B \\
\hline T0 (basal) & $4.0 \pm 1.0$ & $3.7 \pm 2.3$ & $6.3 \pm 1.8$ & $5.2 \pm 2.8$ & $2.5 \pm 1.3$ & $1.5 \pm 0.8$ \\
\hline $\mathrm{Tl}(3 \mathrm{~min})$ & $3.7 \pm 2.4$ & $3.4 \pm 1.9$ & $6.2 \pm 1.9$ & $5.4 \pm 2.2$ & $2.1 \pm 0.6$ & $2.0 \pm 0.7$ \\
\hline $\mathrm{T} 2(10 \mathrm{~min})$ & $5.3 \pm 2.5$ & $4.5 \pm 3.0$ & $8.3 \pm 3.3$ & $6.1 \pm 3.1$ & $2.9 \pm 0.9$ & $1.5 \pm 0.5$ \\
\hline $\mathrm{T} 3(15 \mathrm{~min})$ & $4.9 \pm 2.7$ & $4.8 \pm 3.4$ & $7.9 \pm 3.6$ & $6.8 \pm 3.5$ & $3.2 \pm 2.2$ & $1.8 \pm 0.4$ \\
\hline ANOVA & NS & NS & NS & NS & NS & NS \\
\hline
\end{tabular}

Group A $(n=10): 15 \mu \mathrm{g} \cdot \mathrm{kg}^{-1}$; Group B $(n=10): 30 \mu \mathrm{g} \cdot \mathrm{kg}^{-1} ; \mathrm{RRSmin}=$ minimal resistance of the respiration system; RRSmax $=$ total resistance of the respiratory system; DeltaRRS $=$ delta resistance of the respiratory system. All data mean \pm standard deviation; NS $=$ not significant.

TABLE II Hemodynamic variables in patients receiving alfentanil

\begin{tabular}{lllllll}
\hline & \multicolumn{2}{c}{$\begin{array}{c}\text { Systolic blood pressure } \\
(\text { mmHg) }\end{array}$} & \multicolumn{2}{c}{$\begin{array}{c}\text { Diastolic blood pressure } \\
\text { (mmHg) }\end{array}$} & \multicolumn{2}{c}{$\begin{array}{c}\text { Heart rate } \\
(\text { beats.min }\end{array}$} \\
& Group A & Group B & Group A & Group B & Group A & \multicolumn{1}{c}{ Group B } \\
\hline Post-ETI & $123 \pm 10.2$ & $124 \pm 9.3$ & $76.3 \pm 5.8$ & $77.7 \pm 8.1$ & $67.8 \pm 8.2$ & $67.6 \pm 9.8$ \\
Incision & $116.8 \pm 6.7$ & $125.3 \pm 11.2$ & $76.3 \pm 6.7$ & $74.7 \pm 8.1$ & $68.3 \pm 8.3$ & $69.9 \pm 11.8$ \\
ANOVA & NS & NS & NS & NS & NS & NS \\
\hline
\end{tabular}

Group A $(n=10): 15 \mu \mathrm{g} \cdot \mathrm{kg}^{-1}$; Group B $(n=10): 30 \mu \mathrm{g} \cdot \mathrm{kg}^{-1}$. All data mean \pm standard deviation. ETI = endotracheal intubation; NS $=$ not significant.

No other respiratory or hemodynamic side-effect was recorded during the study and during the surgical procedure.

\section{Discussion}

The main result of this study was the absence of effect of alfentanil on respiratory system mechanics in two groups of ASA I patients undergoing general surgery procedures.

This result is in apparent contrast with the results reported by Ruiz Neto et al. in a study conducted in a group of ten patients in which the effects of alfentanil on the resistance and elastance of the respiratory system, thoracic wall and lungs were assessed. ${ }^{10}$ Respiratory mechanics were assessed by the end-inflation occlusion method, as in the present study. Measurements were performed before drug administration and after two, five and ten minutes, in patients undergoing coronary artery bypass grafting. The authors reported an increase of respiratory system resistance two, five and ten minutes after alfentanil administration, together with a parallel increase in respiratory system elastance (the reciprocal of compliance). The authors also evaluated the effects of fentanyl (30 $\left.\mu \mathrm{g} \cdot \mathrm{kg}^{-1}\right)$ on respiratory system mechanics and observed similar effects. Comparing our results with those reported by Neto, ${ }^{10}$ some differences can be explained by the different doses $\left(120 \mu \mathrm{g} \cdot \mathrm{kg}^{-1}\right.$ vs 15 or $30 \mu \mathrm{g} \cdot \mathrm{kg}^{-1}$ respectively); however, the alfentanil doses we used are those commonly suggested ${ }^{6}$ in clinical anesthesia for procedures lasting less than two hours.

An increase of airway resistance after opioid administration has been reported in several studies, suggesting a possible role played both by histamine release and by an increase in cholinergic tone. ${ }^{21,22} \mathrm{~A}$ significant histamine release was reported by Flacke et al. ${ }^{21}$ after the administration of morphine and pethidine, but has not been reported after alfentanil, sufentanil, fentanyl and remifentanil administration. ${ }^{22,23}$ An increase in cholinergic tone, with a consequent vagomimetic effect, has been demonstrated in experimental animals after fentanyl administration ${ }^{1}$ and could be related to a dramatic reduction in the amount of circulating catecholamines, causing the predominance of cholinergic effects on bronchomotor tone.

Bibault $e t ~ a l .{ }^{24}$ evaluated the effects of general anesthesia with propofol and alfentanil on airway resistance in two groups of patients: nine subjects were free from pulmonary disease, while eight had bronchial hyperreactivity, with a clinical diagnosis of asthma. In all patients, airway resistance was evaluated with the patients breathing spontaneously before surgery, during induction of general anesthesia and after extubation. No significant modification in bronchial tone was reported in both subgroups of patients. The authors concluded that the association of propofol and alfen- 
tanil is safe in patients with bronchial hyperreactivity; the use of propofol, considered to be the agent of choice for the induction of anesthesia in asthmatic patients for its possible bronchodilator effect, ${ }^{25,26}$ could have influenced the effects of alfentanil. We used sodium thiopental and cis- atracurium for the maintenance of anesthesia, as both drugs are free from effects on bronchomotor tone, thus minimizing the risks of pharmacologic interferences. ${ }^{27,28}$ For this reason we avoided the administration of any volatile agent.

When long-term measurements are required (i.e., assessment of modifications over several hours) airway pressure must be measured at the carinal level, ${ }^{19}$ to eliminate possible and progressive modifications of tube resistance (by kinking, secretions or displacement). Our measurements of RRSmin and RRSmax, therefore, do not include the intrinsic resistance of the tube and are technically reliable. The level of anesthesia, muscle relaxation and ventilator settings were kept constant, so any observed modification of respiratory system mechanics should be attributable to the administration of alfentanil.

In conclusion, we have shown that alfentanil $\left(15-30 \mu \mathrm{g} \cdot \mathrm{kg}^{-1}\right)$ has no effect on respiratory system mechanics and airway resistance of ASA I patients ventilated mechanically during general anesthesia.

\section{References}

1 Gentil B, Macquin-Mavier I, Harf A. Fentanyl-induced airway hyperreactivity in the guinea pig. Eur J Pharmacol 1989; 159: 181-5.

2 Cohendy R, Lefrant JY, Laracine M, Rebiere T, Eledjam $J J$. Effect of fentanyl on ventilatory resistances during barbiturate general anaesthesia. Br J Anaesth 1992; 69: 595-8.

3 Yasuda I, Hirano T, Yusa T, Satoh M. Tracheal constriction by morphine and by fentanyl in man. Anesthesiology 1978; 49: 117-9.

4 Cigarini I, Bonnet F, Lorino AM, Harf A, Desmonts $J M$. Comparison of the effects of fentanyl on respiratory mechanics under propofol or thiopental anaesthesia. Acta Anaesth Scand 1990; 34: 253-6.

5 Levy JH, Brister NW, Shearin A, et al. Wheal and flare responses to opioids in humans. Anesthesiology 1989; 70: 756-60.

6 Baley PL, Egan TD, Stanley TH. Intravenous opioid anesthetics. In: Miller RD (Ed.). Anesthesia, 5th ed. 2000; 1: 314-5; 333-4.

7 Taeger K, Weninger E, Schmelzer F, Adt M, Franke N, Peter $K$. Pulmonary kinetics of fentanyl and alfentanil in surgical patients. Br J Anaesth 1988; 61: 425-34.

8 Waters CM, Krejcie TC, Avram MJ. Facilitated uptake of fentanyl, but not alfentanil, by human pulmonary endothelial cells. Anesthesiology 2000; 93: 825-31.

9 de Wet C, Moss J. Metabolic functions of the lung. Anesthesiol Clin North Am 1998; 16: 181-99.

10 Ruiz Neto PP, Auler JOC Jr. Respiratory mechanical properties during fentanyl and alfentanil anaesthesia. Can J Anaesth 1992; 39: 458-65.

11 Bryson HM, Faulds D. Cisatracurium besilate. A review of its pharmacology and clinical potential in anaesthetic practice. Drugs 1997; 53: 848-66.

12 Sly PD, Bates JH, Milic-Emili J. Measurement of respiratory mechanics using the Siemens Servo Ventilator 900 C. Pediatr Pulmonol 1987; 3: 400-5.

13 Bates JH, Hunter IW, Sly PD, Okubo S, Filiatrault S, Milic-Emili J. Effect of valve closure time on the determination of respiratory resistance by flow interruption. Med Biol Eng Comput 1987; 25: 136-40.

14 Similowski T, Levy P, Corbeil C, et al. Viscoelastic behavior of lung and chest wall in dogs determined by flow interruption. J Appl Physiol 1989; 67: 2219-29.

15 D'Angelo E, Calderini E, Torri G, Robatto FM, Bono D, Milic-Emili J. Respiratory mechanics in anesthetizedparalyzed humans: effect of flow, volume, and time. J Appl Physiol 1989; 67: 2556-64.

16 Milic-Emili J, Robatto FM, Bates JHT. Respiratory mechanics in anaesthesia. Br J Anaesth 1990; 65: 4-12.

17 Johnson A, Bengtsson M. Comparison of anaesthesia ventilators using a lung model. Acta Anaesthesiol Scand 1990; 34: 222-6.

18 D'Angelo E, Robatto FM, Calderini E, et al. Pulmonary and chest wall mechanics in anesthetized paralyzed humans. J Appl Physiol 1991; 70: 2602-10.

19 Conti G, De Blasi RA, Lappa A, et al. Evaluation of respiratory system resistance in mechanically ventilated patients: the role of the endotracheal tube. Intensive Care Med 1994; 20: 421-4.

20 Petros AJ, Lamond CT, Bennett D. The Bicore pulmonary monitor. A device to assess the work of breathing while weaning from mechanical ventilation. Anaesthesia 1993; 48: 985-8.

21 Flacke JW, Flacke WE, Bloor BC, Van Etten AP, Kripke $B J$. Histamine release by four narcotics: a double- blind study in humans. Anesth Analg 1987; 66: 723-30.

22 Bowdle TA. Adverse effects of opioid agonists and agonist -antagonists in anaesthesia. Drug saf 1998; 19: 173-89.

23 Lien CA, Belmont MR, Abalos A, et al. The cardiovascular effects and histamine-releasing properties of 51W89 in patients receiving nitrous oxide/opioid/barbiturate anesthesia. Anesthesiology 1995; 82: 1131-8.

24 Bilbault P, Boisson-Bertrand D, Duvivier C, Peslin R, Laxenaire MC. Influence de l'association propofolalfentanil sur les resistances bronchiques du sujet asthmatique (French). Ann Fr Anesth Reanim 1991; 10: 264-8. 
25 Bremerich $D H$. Anesthesia in bronchial asthma

(German). Anasthesiol Intensivmed Notfallmed Schmerzther 2000; 35: 545-58.

26 Hirota $K$, Sato T, Hashimoto $\Upsilon$, et al. Relaxant effect of propofol on the airway in dogs. Br J Anaesth 1999; 83: 292-5.

27 Mustafa S, Thulesius L, Thulesius O. The contractile response of thiopental in large and small ovine airways. Acta Anaesthesiol Scand 1994; 38: 499-504.

28 Wu RSC, Wu KC, Sum DCW, Bishop MJ. Comparative effects of thiopentone and propofol on respiratory resistance after tracheal intubation. Br J Anaesth 1996; 77: 735-8. 